\title{
El mapa al millonésimo de Hispano América. Una Empresa Cooperativa Inter Americano, ${ }^{1,2}$
}

\author{
The map to the millionth of Hispano America. An Inter-American \\ Cooperative Company
}

\section{O mapa do milionésimo da América Hispano. Uma empresa cooperativa interamericana}

\author{
Isaiah Bowman (+) \\ Johns Hopkins University
}

\section{RESUMEN}

En este discurso de Isaiah Bowman, se nos muestra como un reconocido referente clásico de la escuela norteamericana de geografía y su relación con Hispanoamérica, en donde Bowman manifiesta la gran importancia que cumplen los mapas a la hora de orientar la política y también en la realización de las actividades económicas, siendo el mapa es un instrumento técnico y no una mera ilustración atrayente, transcendiendo de una simple utilización como instrumento bélico en donde la información es poder por lo tanto es clave. Bowman realiza un análisis de caracterización sobre la cartografía oficial de Perú, Chile, Argentina, Bolivia y Brasil, lugares que visitó gracias a las expediciones de la Universidad de Yale entre 1907 y 1913. Bowman en sus obras que no solo se limitó a la geografía física de los andes centrales de Sudamérica o los andes del sur del Perú, también recolecto mucha información sobre la opresión y explotación del indígena, del problema de la tierra y el latifundio, de cómo hasta la fecha donde el viajo se explotaba al indio sin ninguna retribución económica, ese quizás es parte de su legado sobre el estudio del Perú, porque sus obras fueron consultadas por diversos académicos peruanos y peruanistas al respecto de la sociedad andino - amazónica en los primeros años del siglo XX. Mención aparte es el proceso de modernización de la cartografía con la mejora de los procesos técnicos en el siglo XX, con ello su uso e importancia en la construcción de los estados y de la relación hegemónica de EE. UU con Latinoamerica y el Caribe hasta la fecha. Agregando la relación entre país y la escala de la cartografía, dando entender la problemática que habría cuando se hablaría de un Mapa Millonésimo de Hispano América; el interés del texto se base alrededor de este proyecto planteado del Mapa Millonésimo de Hispano América comentando sobre los esfuerzos, avances y la cooperación de distintos gobiernos e instituciones para la elaboración de este proyecto luego de la I Guerra Mundial 1914 - 1918. El Mapa al Millonésimo de Hispano América sería la

1 Esta conferencia fue leída por su autor en el Salón General de la Universidad, la mañana del 13 de Julio. Se publica en la Revista Universitaria por cortesía del Dr. Federico Ponce de León, Presidente del Centro Geográfico Cuzco, quien obtuvo los originales y el privilegio de publicarlos en el primer número del Boletín de dicho Centro, Anteriormente, el mismo Dr. Ponce de León, publicó la introducción de la misma, en la edición del 28 de Julio pasado en el diario "EL COMERCIO" de esta ciudad. - N. de la R.

2 [Nota de la redacción] El texto original fue redactado por Rafael Yépez La Rosa y publicado por la Universidad Nacional San Antonio Abad del Cusco en la Revista Universitaria Año XXX Nro 80 Primer Semestre de 1941. pp. 207-295. Cuzco-Perú. La transcripción es original y no se ha modificado el texto, se acusa revisiones ortográficas, usos de significados y significantes de la época. Se le modifico al formato de esta revista, se le agregaron los resúmenes, la bibliografía del autor y los comentarios a modo de conclusiones de un cercano colaborador norteamericano. geografías y ciencias sociales, 3(5), 117-128. https://dx.doi.org/10.15381/espiral.v3i5.21183 
base del Gran Atlas Panamericano, desde una visión de la Sociedad Geográfica Americana (AGS en inglés) y esto fue acordado En la segunda Asamblea del instituto Panamericano de Geografía e Historia - IPGH órgano técnico adscrito a la OEA, ¿quizás ahí se debe la importancia del porque el interés era solo técnico o era geopolítico?, o lo que es más interesante el interés del gobierno de Estados Unidos de cartografiar el borde costero del Océano Pacifico de nuestro continente desde Tierra del Fuego hasta Alaska, para salvaguardarnos de futuras invasiones de otros continentes.

\section{ABSTRACT}

In this speech by Isaiah Bowman, we are shown as a recognized classic reference of the North American school of geography and its relationship with Latin America, where Bowman manifests the great importance that maps play in guiding politics and also in the realization of economic activities, since the map is a technical instrument and not a mere attractive illustration, transcending a simple use as a war instrument where information is power, therefore it is key. Bowman performs a characterization analysis on the official cartography of Peru, Chile, Argentina, Bolivia and Brazil, places that he visited thanks to the Yale University expeditions between 1907 and 1913. Bowman in his works that he was not only limited to the physical geography of the central Andes of South America or the Andes of southern Peru, he also collected a lot of information on the oppression and exploitation of the indigenous, the problem of land and latifundio, how Until the date where the traveler was exploited the Indian without any economic retribution, that perhaps is part of his legacy on the study of Peru, because his works were consulted by various Peruvian and Peruvian academics regarding the Andean-Amazon society in the first years of the twentieth century. A special mention is the process of modernization of cartography with the improvement of technical processes in the twentieth century, with it its use and importance in the construction of states and the hegemonic relationship of the United States with Latin America and the Caribbean until the date. Adding the relationship between the country and the scale of the cartography, suggesting the problems that would arise when speaking of a Millionth Map of Hispano America; The interest of the text is based around this project proposed for the Millonth Map of Hispano America, commenting on the efforts, advances and cooperation of different governments and institutions for the elaboration of this project after World War I 1914 - 1918. The Map to the Millionth of Hispano America would be the base of the Great Pan American Atlas, from a vision of the American Geographical Society (AGS in English) and this was agreed at the Second Assembly of the Pan American Institute of Geography and History - PAIGH technical body attached to the OAS, perhaps there is the importance of why the interest was only technical or geopolitical? Or, what is more interesting, the interest of the United States government to map the coastline of the Pacific Ocean of our continent from Tierra del Fuego to Alaska, to safeguard us from future invasions from other continents.

\section{RESUMO}

Neste discurso de Isaiah Bowman, somos apresentados como uma referência clássica reconhecida da escola de geografia norte-americana e sua relação com a América Latina, onde Bowman manifesta a grande importância que os mapas desempenham na orientação da política e também na realização das atividades econômicas, visto que o mapa é um instrumento técnico e não uma simples ilustração atrativa, transcendendo um simples uso como instrumento de guerra onde informação é poder, portanto é fundamental. Bowman faz uma análise de caracterização da cartografia oficial do Peru, Chile, Argentina, Bolívia e Brasil, lugares que visitou graças às expedições da Universidade de Yale entre 1907 e 1913. Bowman em suas obras que não se limitou apenas à geografia física dos Andes centrais da América do Sul ou dos Andes do sul do Peru, ele também coletou muitas informações sobre a opressão e exploração dos indígenas, o problema da terra e latifúndios. , como Até a data em que o viajante foi explorado o índio sem qualquer retribuição econômica, que talvez faça parte de seu legado no estudo do Peru, pois suas obras foram consultadas por diversos acadêmicos peruanos e peruanos a respeito da sociedade andino-amazônica no primeiro anos do século XX. Uma menção especial é o processo de modernização da cartografia com o aprimoramento dos processos técnicos no século $X X$, com sua utilização e importância na construção dos Estados e na relação hegemônica dos Estados Unidos com a América Latina e o Caribe até a data. Somando a relação entre o país e a escala da cartografia, sugerindo os problemas que surgiriam ao se falar de um Mapa Milionésimo da Hispano América; O interesse do texto é baseado neste projeto proposto para o Mapa Milenar da Hispano América, comentando os esforços, avanços e cooperação de diferentes governos e instituições para a elaboração deste projeto após a Primeira Guerra Mundial 19141918. O Mapa ao Milionésimo da Hispano América seria a base do Grande Atlas Pan-Americano, a partir de uma visão da American Geographical Society (AGS em inglês) e isso foi acordado na Segunda Assembleia do Instituto Pan-Americano de Geografia e História - Órgão técnico do IPGH vinculado à OEA, talvez haja a importância de porque o interesse era apenas técnico ou geopolítico? Ou, o que é mais interessante, o interesse do governo dos Estados Unidos em mapear a costa do Oceano Pacífico de nosso continente a partir da Terra del Fuego para o Alasca, para nos proteger de futuras invasões de outros continentes.

PALABRAS CLAVES: Hispanoamérica; Atlas; Mapa al Millonésimo; Cartografía.

KEYWORDS: Hispanic America; Atlas; Map to the Millionth; Mapping.

PALAVRAS CHAVES: América Hispânica; Atlas; Mapa até o milionésimo; Mapeamento. 
Ningún estadista moderno podría dirigir sus actos diarios ni orientar su política sin un mapa que indique posiciones, distancias objetivos y fronteras. Los leaders industriales se han dado cuenta que el mapa es un instrumento técnico y no una mera ilustración atrayente. El lector del periódico exije que las noticas se hallen expuestas e interpretadas por medio de mapas especialmente diseñados y publicados día por día, en estrategia militar un mapa es una especie de "información". Napoleón tenía pasión por los mapas y poseía una excelente colección para estudiar los desfiladeros obstáculos, distancias y objetivos de sus campañas. Los gobernantes piden mapas que indiquen la habitación, los pueblos y sus recursos. Ellos preguntan insistentemente. "Donde se encuentra aquello que pueda estar sujeto a impuestos o contribuciones?",

Los mapas antiguos, hechos a mano y en ejemplare únicos, eran raros y costosos; los mejores de éstos se encontraban en manos de los príncipes y los ricos únicamente. Los primeros mapas impresos se hicieron una generación antes que el viaje de Cristóbal Colón. Fué solamente entonces que, por primera vez en la historia, el papa impreso en blanco y negro se abarató y así, pudo vulgarizarse. Con los adelantos técnicos en materia de litografía, las calidades de la tinta, del papel y el arte de dibujante, los mapas han ganado en precisión y utilidad. El cartógrafo ha respondido al requerimiento que hoy existe para miles de usos diferentes. El mapa moderno es un sistema de anotación, un idioma universal, una base para representaciones especializadas y un para señalar el lugar donde se encuentran las cosas. Una edición de primera clase de mapas que indicara el amplio campo que abarcan aquellos usos modernos no podría tener menos de cien mil hojas,

Hay un término castellano, "mapa mundo" que corresponde en significado a la expresión francesa "carte muette", Esto quiere decir un mapa silencioso o "mudo". Un mapa mudo, o "Base map" (mapa base), para emplear el término inglés, es una cosa desnuda y desprovista de interés para el profano, algo sin personalidad ni belleza $y$, en realidad, se ha dispuesto que así fuera. En una palabra, el mapa en sí es silencioso: peo lo que se ponga sobre él, habla. Esta es una representación hecha por los geógrafos expresamente para mostrar diferentes distribuciones. Se señalan en éstos mapas tan sólo los contornos de las costas, el curso de los ríos, los límites de las divisiones y subdivisiones administrativas (de acuerdo con los cuadros estadísticos) y, acaso, la situación de algunas ciudades. Finalmente, debe contemplarse el punto importante que se refiere a la escala, meridianos y paralelos, sin los cuales un mapa deja de serlo.

Cuando el mapa de distribución confeccionando sobre la base muda se encuentra ante nosotros, debe hablarnos claramente sobre la producción y reservas mineras, bosques, población, y muchas otras clases de asuntos. Un mapa de este título puede mostrar las áreas y tipos de medio ambiente en que la malaria o la fiebre amarilla son endémicas; otro indicará los límites de un distrito asolado por una plaga de langostas; orea más, los lugares apropiados para irrigaciones o donde haya más posibilidad de utilizar la fuerza hidráulica, la extensión en que el gusano de capullo malogró la cosecha de algodón o mosaico ha perjudicado al hacendado en sus sembríos de tabaco; también podrá mostrar las zonas en que se encuentran los crustáceos que constituyen el principal alimento de las ballenas del Antártico, que son la base de la industria del aceite de este cetáceo; o el crecimiento de las regiones en que hay suelos donde se producen erosiones, o tierras improductivas; o el radio de distribución alcanzado por algún diario metropolitano (y su publicidad) en distritos urbanos $\mathrm{u}$ los pueblos circunvecinos; la frecuencia de los incendios forestales en los bosques cuya extensión decrece; las zonas en que se presenta el reumatismo en relación con las zonas de temperatura del mundo o el campo de diversos sistemas legales bajo los cuales las sociedades humanas han desarrollado sus códigos y leyes.

Después de leer esta relación de algunas de las cosas que, entre muchas otras, los geógrafos expresan por medio de mapas, se podrá comprender por qué hablamos del "idioma del mapa". Una manera especial de escritura. Todos sus signos son 
convencionales, es decir que se repiten muchas veces de la misma manera. A pesar del hecho que cada geógrafo se toma ciertas libertades con los símbolos y convenciones cartográficas, así como lo hacemos con las palabras del lenguaje ordinario, es, sin embargo, cierto que las indicaciones de un papa pueden ser leídas e interpretadas en la mayoría de los países civilizados del mundo. El idioma de los mapas es, por tanto, universal- Toda persona que ha ido al colegio ha estudiado los mapas, porque una de las preguntas más importantes que deben aprende a absolver los ciudadanos futuros es: "Donde vivo yo?". Aún en el caso que no le interese a uno este sujeto, no se puede menos que tomar en cuenta los lugares y espacios donde viven las demás gentes.

Lo primero que deberá decidir el cartógrafo, antes de comenzar un mapa, es la escala que empleará. Si desea mostrar la ubicación de los Continentes y nada mas, puede servir una representación del tamaño de la uña del dedo pulgar. En cambio, si quiere indicar claramente todas las ciudades del mundo cuya población excede los treinta y cinco mil $(35,000)$ habitantes con sus nombres, el mapa resultante sería del alto de un hombre. Un aviador que volara desde Baltimore hasta Lima, no podría llevar ni utilizar un mapa a escala de una pulgada por cada milla, lo que es una proporción popular y práctica para caminantes. ¡A doscientas (200) millas por hora, el piloto necesitaría, para este lapso de tiempo doscientas (200) pulgadas de mapa confeccionado a esa escala! Un plano catastral o de la propiedad muestra las líneas que demarcan los linderos de los terrenos individuales. Un mapa de esta clase para todo el Perú o los Estados Unidos tendría tantas hojas y sería tan pesado que habría que emplear un camión para llevarlo de un lado a otro. La escala de un mapa se determina según la conveniencia y facilidad de lectura. Los geógrafos y cartógrafos hacen mapas para un fin determinado, y hay muchos fines. Se podría decir: Muéstreme los mapas de un país y les diré el grado de su civilización. En una palabra, les dirá cuántas clases de fines progresistas ha desarrollado con relación a sus recursos, su pueblo, sus defensas, sus ciudades y sus intercambios culturales.

El objeto de esta disertación es describir una serie completa de mapas que se han confeccionado para toda la América Latina y que representan el trabajo cartográfico más amplio que haya sido ejecutado por una organización privada. La importancia de ésta empresa en cuanto al mapa futuro de la América Latina a efectuarse por los diferentes países interesados, y su valor en la investigación científica, se harán evidentes más adelante. Constituye, a la vez, un mapa base y topográfico, ya que tiene los elementos esenciales de una base, así como las capas de colorido que revelan los grandes relieves. Una necesidad común para la interpretación de cualquier distribución-elementos climatéricos, población, transportes, etc.- es la indicación de tierras bajas y de altiplanicies, desfiladeros que cruzan las cordilleras, las alturas y los ríos.

Cuando visité el Perú primera vez en mil novecientos siete (1907), y luego en mil novecientos once (1911) u mil novecientos trece (1913), el mejor mapa del país era el de Raimondi (Mapa del Perú, escala uno por quinientos mil 1: 500,000) que era una compilación verdaderamente notable. Lo llevaba en mi bolsillo al cruzar los senderos de la Cordillera y al bajar el curso del Urubamba en canoa hasta las orillas cubiertas de selva de la cuenca amazónica. La indicación de ciudades y cadenas de montañas estaba frecuentemente equivocada, pero esto sucede siempre con todos los primeros mapas compresivos. Los mapas primitivos no pueden ser correctos en todos sus detalles, porque son una mezcla de algunas observaciones exactas y muchas informaciones verbales erradas- Pueden incluir levantamientos de rutas por observaciones astronómicas y cronométricas o por señales de tiempo telegráficas o inalámbricas; o adivinando distancias entre las ciudades o los pasos de las montañas y volcanes, de acuerdo con informaciones de los guías; es decir que son una relación ordenada de algunos datos precisos y otros inexactos. Los primeros mapas del nuevo mundo son de este tipo. Algunos de los detalles eran vagamente recordados por 
navegantes y descritos ligeramente a los cartógrafos y dibujantes, quienes nunca vieron, ni mucho menos midieron, los nuevos litorales que se les mandaba delinear. Pero estos mapas primitivos señalaban con sorprendente claridad el contorno general de las costas, aunque la mayoría de sus detalles eran desconocidos. Eran exactos como se necesitaba que fuesen, tal vez, en relación a los fines elementales de la época. Finalmente, ningún mapa que se haya hecho es estrictamente preciso. Es financieramente, si no técnicamente, imposible hacer el mapa de un país grande que indique cada detalle apropiado a una escala dada. Los mapas son sólo representaciones relativamente exactas.

Hace muchos años, diversos viajes a Sud América, -en el Perú, Chile, Argentina, Bolivia y Brasil- debía siempre formar la compilación del mapa de la región que iba a visitar con el fin de estudiarla detenidamente antes de emprender el viaje. No podía establecer en el campo los límites de las formaciones y estructuras de las rocas, representar los tipos geomorfológicos o la distribución de la población, bosques o sembríos, sin un mapa mudo. Establecer un mapa base para anotaciones, personales sobre el campo, es una empresa que demanda mucho tiempo y resulta muy onerosa para el individuo. Me parecía que todos los estudios geográficos de la América Latina se acelerarían y ganarían en exactitud y utilidad si la labor de compilación de un mapa para uso general fuera hecha por una institución donde se centralizarían todos los levantamientos topográficos originales. Además, los historiadores, economistas, selvicultores, ingenieros, aviadores, navegantes, arqueólogos, estadistas, exploradores y geógrafos, se beneficiarían con la publicación de un mapa general de esta naturaleza, ejecutado según los standards más altos de nuestros tiempos.

Al término de la guerra de mil novecientos catorce a mil novecientos dieciocho (1914 - 1918), cuando pudimos reasumir nuestras costumbres civilizadas, yo formulé un proyecto titulado "El Mapa Millonésimo de Hispano América". Destinado a ser una extensión de aquel vasto dominio de la serie general "millonésima" (para el mundo entero), cuyos colores, estilo, etc., (es decir, convenciones cartográficas) fueron establecidos y acordados por un grupo internacional de representantes elegidos por cada país, reunido en Londres en mil novecientos nueve (1909). La palabra "millonésimo" se deriva de la escala siguiente: un millón de pulgadas de extensión natural se representa por pulgada en el mapa (es decir 15.8 millas para una pulgada o un kilómetro por cada milímetro). Afortunadamente la Sociedad Geográfica Americana, de la que yo era entonces Director, estaba formada por un grupo de hombres generoso y de clara visión, y ellos apoyaron el proyecto. Durante los veinte años transcurridos desde ese tiempo, todo un personal de recopiladores, dibujantes y editores ha estado trabajando continuamente en el Mapa Millonésimo de Hispano América. El Profesor Alan Ogilvie, hoy Miembro de la Universidad de Edimburgo, fue el primero encargado de esta obra por un período de tres años; en los doce años subsiguientes la dirigió el Doctor Raye R. Platt, de la Sociedad Geográfica Americana. El actual Director es el Doctor Charles B. Hitchcock. La serie de ciento siete (107) mapas que comprende el proyecto está ahora enteramente recopilada y la última hoja se terminará de imprimir en pocos meses. El trabajo que se ha hecho para esta colección que cubre un área de doce millones $(12.000,000)$ de millas cuadradas de mar y tierra, de haberlo emprendido un hombre solo, hubiera demorado doscientos (200) años. Las dimensiones mayores que tiene el mapa son de treinticuatro por veintiocho pies $(34 \times 28)$. Bate todos los records alcanzados por los planos conocidos hechos en las oficinas de los diversos gobiernos hispanoamericanos, por las de construcciones nacionales y extranjeras, las compañías fomento industrial, agrícola o de explotación, o por exploradores científicos. Se dió acceso a la Sociedad a centenares de colecciones de mapas publicados e inéditos de los archivos de oficinas gubernativas y particulares en los países latinoamericanos y en los Estados Unidos. El personal de la Sociedad ha recorrido, igualmente, las obras literarias, geográficas y de ciencias conexas, para 
determinar todos los planos hechos durante los últimos cuatro siglos, y todas las descripciones que pudieran contribuirá a la precisión del Mapa.

En la confección de cualquier plano general de países cuyo territorio tiene zonas aún no completamente levantadas topográficamente o por otros medios, de haber, forzosamente, partes que se hanllenado tomando datos de cartas geográficas primitivas o mapas recopilados clásicos. El período colonial de la historia hispanoamericana dio origen a una serie notable de mapas y atlas compilados de cuyas fuentes se tomaron datos para la confección del Mapa al millonésimo. A mediados del siglo diecinueve (XIX), se produjo otro gran movimiento de actividad cartográfica. Este fue el período de Codazzi en Colombia y Venezuela, Pissis en Chile, Raimondi en el Perú y Wolf en el Ecuador. Mucho del material dejado por éstos tiene valor todavía y permanentemente útil porque está basado en levantamientos locales por medio de instrumentos.

Con el advenimiento del siglo veinte $(X X)$ sin embargo, este trabajo de recopilación no siguió el paso de las crecientes y numerosas observaciones que se multiplicaban rápidamente, con el fin de batir records de exploraciones, desarrollar la explotación de recursos naturales o construir nuevas redes de transportes. Los levantamientos topográficos sistemáticos emprendidos por muchos de los gobiernos, eran fuentes de valor excepcional pero lentas en su desarrollo. (Esto se aplica a los Estados Unidos: hasta la fecha se ha hecho esta clase de mapas en solamente mitad de nuestro territorio). Había abundante material cartográfico, pero mucho de éste no era fácilmente accesible al recopilador de mapas. La Sociedad Geográfica Americana se dedicó a coleccionar y clasificar este rico acopio de informaciones. El resultado de esta tarea ha sido no sólo un mapa notable sino una serie catalogada de fuentes de material: el "Catálogo de los Mapas de Hispanoamérica" en cuatro Tomos que presenta, en orden cronológico, la lista de planos de cada país que se encuentran en siete de las colecciones de mapas de la América latina más completas de los Estados Unidos; una serie de monografías sobre los Andes Centrales, Perú, Chile, y la República Argentina, etc. y artículos sobre cada región principal y en casi todos los campos de interés geográfico de la América Latina, publicados en el órgano trimestral de la Sociedad: la "Revista Geográfica".

La cooperación prestada por las numerosas reparticiones de los gobiernos hispanoamericanos e instituciones científicas, compañías ferrocarrileras, petrolíferas y de ingeniería, y la ayuda individual recibida tanto en la América Latina como en los Estados Unidos al proporcionar informaciones originales para el Mapa, representa uno de los intercambios culturales más admirables en la historia del hemisferio occidental. Un representante de la Sociedad, que visitó los diversos países de la América del Sur en busca de Material para la obra, obtuvo en estos países toda clase de facilidades, como el libre acceso a colecciones inestimables de planos inéditos que formaban parte de archivos nacionales y particulares. Los gobiernos que tienen programas de levantamientos topográficos sistemáticos desde hace muchos años, no solamente han proporcionado, casi sin excepción, a la Sociedad los nuevos planos de sus observaciones tan pronto como han salido de prensa, sino también han enviado copias de levantamientos que, en muchos casos, no estaban todavía incluidos en las hojas publicadas- La Comisión de irrigación del Perú y el Servicio Geográfico del Ejército han proporcionado cientos de mapas que mostraban levantamientos topográficos recientes. El Ecuador, al remitir una colección completa de los mapas de su Ministerio de Obras Públicas, acompañó el envío con un delegado del gobierno, quien quedó en los Estados Unidos para estudiar la ciencia y el arte de la confección de mapas en la Sociedad Geográfica Americana.

En Colombia, los gobiernos departamentales, así como el federal, cooperaron generosamente; los gobernadores de los diferentes departamentos de la República remitieron mapas manuscritos de sus jurisdicciones que señalaban los límites de pequeñas subdivisiones administrativas y otras informaciones que no se conseguían en ninguno de los mapas publicados. El Director de la oficina de Longitudes fue 
consultado en muchas oportunidades por cable y cartas aéreas durante el tiempo en que se efectuó la confección de los planos correspondientes a Colombia. En la República Argentina, Chile y Uruguay, los Institutos Geográficos Militares, Los Servicios Geográficos, las Direcciones de Minas, han suministrado enormes cantidades de los diversos estados ocupados en la ejecución de programas de levantamientos topográficos han enviado continuamente copias de éstos para completar la colección de la Sociedad; los geógrafos más sobresalientes han cooperado en la solución de problemas de compilación y el Ministerio de Relaciones Exteriores ha contribuido generosamente con copias manuscritas de demarcaciones de límites y otras fuentes de información.

El Gobierno de Venezuela también ha proporcionado mucho material original $\mathrm{y}$, como en el caso de Colombia, ha sido posible absolver rápidamente numerosas consultas a funcionarios del gobierno o a particulares por medio del correo aéreo. El Presidente de la República de Panamá tomó un interés personal en la confección de la sección del mapa que correspondía a su territorio; envió su Secretario a la Sociedad con informaciones originales e influyó para que se adoptara como mapa oficial de Panamá, uno que reprodujo de acuerdo con los diseños originales que se prepararon para el Mapa Millonésimo. Todos los Gobiernos Centroamericanos han cooperado galantemente Costa Rica, Nicaragua, Honduras, Guatemala y El Salvador. La Dirección de Estudios Geográficos y Climatológicos del Gobierno Mejicano y otras oficinas gubernamentales nos han prestado su ayuda constante en el momento en que se confeccionaron los planos mejicanos. En todas las Repúblicas Hispanoamericanas, las oficinas de Censo y Estadísticas han proporcionado datos y cifras sobre las que se ha basado la clasificación de pueblos y ciudades.

Finalmente, las expediciones enviadas por la Sociedad, o dirigidas por amigos de la Sociedad, para determinar levantamientos en áreas críticas para las que no existían informaciones precisas como, por ejemplo, la expedición de mil novecientos veintisiete (1927) a las fuentes del Marañón en el área central del Perú, han sido debidamente atenidas, habiéndoles dado los gobiernos, las instituciones científicas y los particulares interesados, todas las facilidades y ayuda posible en estos países latinoamericanos. Es solamente mediante esta cooperación que ha sido posible confeccionar este gran Mapa en el que cada país ha invertido una cantidad apreciable de material y tanta buena voluntad.

Hay algunas cosas que un solo individuo o una institución pueden hacer que sobreviva como una fuerza o influencia activas en las generaciones venideras. Volvemos siempre los ojos al mapa de Hecateo con el mismo interés; a la autonomía de Hiparco, que calculó certeramente el ciclo lunar y dio impulso a aquella ciencia de la cual la navegación y la exploración llegaron a depender; a Ptolomeo y su determinación de las distancias y los puntos de orientación costera para los navegantes. El mapa mundial de Leardo (1453) todavía nos llama la atención porque nos enseña hasta a donde los pueblos de aquella época creían que llegaban los límites de la Tierra. Algunas de sus otras opiniones eran derivadas o condicionadas por el concepto que tenían de su universo. Esto es, a veces, tan importante para los estudios históricos como si la representación de sus mapas y su pensamiento hubieran correspondido a la realidad. El trascurso del tiempo ha fomentado y no disminuido nuestro interés por éstas grandes empresas, y el tiempo, también, así lo esperamos, será tan generoso para la obra del mapa Millonésimo. Mientras la mayoría de los primeros mapas eran hechos por geógrafos y cartógrafos individuales, los de nuestros días representan la labor de muchas personas clasificadores, topógrafos, compiladores, dibujantes, editores, geógrafos. La cartografía, en los últimos cien años, se ha convertido y se afirma más y más como el resultado del constante mejoramiento de los equipos de los equipos instrumentales de campo y de laboratorio y del conocimiento técnico de su aplicación. 
En los nuevos países del Norte y Sud América donde existen grandes áreas que no han sido sometidas todavía a levantamientos topográficos sistemáticos, todos los mapas recopilados como el Mapa Millonésimo de Hispano América. Estas compilaciones se basan en una gran variedad de informaciones que tienen diversos grados de exactitud y detalle. Es, por lo tanto, importante que aquel que consulte este mapa sepa la calidad del material que se ha empleado en la confección de cualquiera de sus secciones particulares. La Sociedad Geográfica Americana, con este fin, ha hecho imprimir cada hoja de su Mapa de hispano América un "Diagrama de Seguridad Relativa" en el cual se indica, por medio de símbolos convencionales, los diferentes tipos de observaciones empleadas en la ejecución de una hoja dada. Al no obtenerse ninguna clase de datos referentes a cierta área, los lineamientos del mapa hubieron de determinarse de acuerdo con mapas anteriores, descripciones de viajeros, fotografías, etc. El diagrama de seguridad relativa indica la excelencia o la deficiencia del material original de cada sección del mapa. Le presta a la obra una cualidad científica al revelar los grados de diferencia en la precisión de las mediciones básicas.

El Mapa Millonésimo de Hispano América es sólo un principio, Ningún mapa puede representar el fin de la empresa cartográfica. En materia de ciencia no hay puntos finales. Cada adelanto induce el espíritu curioso a alcanzar nuevas metas. Cuando se señala un error en el Mapa Millonésimo, se le corrige. Al completarse un nuevo levantamiento, se le reduce al millonésimo y se le incorpora. A veces un informe referente a nuevas exploraciones localiza ciudades o ríos, o establece distancias con mayor exactitud que aquellas obtenidas en determinaciones anteriores. El Mapa crece continuamente a medida que aumenta el conocimiento de sus elementos constituyentes. Miles de personas han contribuido en su producción y miles más participarán en su perfeccionamiento.

Ha servido ya para fines importantes y notablemente en conexión con negociaciones limítrofes. Por ejemplo, fue empleada como plano oficial por las comisiones plebiscitarias y delimitadoras que actuaron bajo las órdenes de los Generales Morrow y Pershing. Un mapa de la región del Chaco que fue preparado por compilación de las hojas correspondientes a Bolivia y Paraguay fue empleado como documento oficial por el Comité de Investigación y Conciliación, en sus sesiones de Washington, mil novecientos veintinueve (12) en relación con el conflicto Paraguayo - Boliviano y, más tarde, como base para el mapa que acompañó el informe elevado ante la Comisión del Chanco de la Liga de las Naciones. Los Gobiernos de Perú y Colombia usaron las hojas apropiadas del mapa Millonésimo para dilucidar la controversia de Leticia. Los ejemplares de la recopilación efectuada para la sección que corresponde a la zona demarcada de la frontera Colombiano-Venezolana en la Sierra de Perijá fueron empleados en el mismo campo en mil novecientos treinta y tres por la Comisión Mixta de Límites. El Mapa Millonésimo ha servido también como carta de navegación aérea en muchas secciones de la América Latina y los exploradores lo van considerando cada día más como parte de su equipo de campaña standard.

Ese centenar de hojas abre un campo de posibilidades en materia de estudios seccionales que los geógrafos serán los primeros en apreciar. Se puede ahora comenzar a una nueva empresa cartográfica cooperativa e iniciar otro período en la ciencia geográfica. Tomando por base los Mapas Millonésimos, se podrá determinar sobre un plano comprensible de escala uniforme los datos comparables en meteorología y climatología, recursos hidráulicos, depósitos de minerales de importancia económica, suelos, estructuras de las rocas, panoramas culturales, arqueología y antropología, vida vegetal y animal, población, etc.

Si se emprendiera labor con el suficiente respaldo financiero, y si los geógrafos de este hemisferio cooperasen en ella como lo han hecho los gobiernos, las compañías constructoras y los individuos particulares para completar el Mapa Millonésimo de Hispano América, no tardaría en editarse el Gran Atlas Panamericano. Podemos 
tener la certeza que si esto se realizara tendríamos, mediante el uso continuo de una publicación tan práctica, un medio muy eficaz para fomentar un mayor interés en las relaciones de vecino a vecino en el hemisferio occidental.

La Sociedad Geográfica Americana ha tenido este Atlas en mente desde hace muchos años. En la Tercera Asamblea del instituto Panamericano de Geografía e Historia celebrado en Lima en abril del año en curso, un Representante de la Sociedad propuso este proyecto, cuya aprobación unánime motivó el siguiente acuerdo.

\section{Atlas de las Américas}

Considerando que el Instituto Pan-Americano de Geografía e Historia reconoce que los mapas son auxiliar muy esencial para que se entienda la vida y las actividades de las Repúblicas de este Continente;

Considerando que la Segunda Asamblea Panamericana de Geografía e Historia adoptó por unanimidad de votos la resolución VI, o sea su expresión del gran valor por investigación en muchas ramas del saber humano que atribuyó al Mapa de la América Latina de la escala de uno a un millón elaborado por la American Geographical Society of New York;

Considerando que la American Geographical Society of New York, ha acumulado ya mucho material para un Atlas de las Américas, que debe editarse próximamente para publicarse por entregas, que representarán las condiciones físicas, económicas y sociales en este Continente;

Por tanto:

Se acuerda:

Que la Tercera Asamblea General Panamericana de Geografía e Historia apoye calurosamente el comprensivo proyecto de la American Geographical Society of New York para la próxima publicación del Atlas de América; el que servirá como obra constante de consulta, y que en su consecuencia contribuirá a un mejor y más exacto entendimiento de los problemas de interés e importancia vitales de la vida y actividades de las Repúblicas en este Continente.

Para el fin del presente año, se contará como base para la sección hispanoamericana de este Atlas, con un mapa de tres hojas a escala de uno en cinco millones $\left(1: 5^{\prime} 000,000\right)$ que abarca desde la frontera de Méjico con los Estados Unidos hasta el Cabo de Hornos, en cuya confección trabaja activamente en la actualidad la Sociedad Geográfica Americana. En este mapa está reduciéndose del Mapa Millonésimo, y representará también la investigación, conocimientos y habilidad técnica empleados en la confección de ese mapa original. Será también un mapa topográfico, en el cual la topografía se expresará por medio de contornos y tintas hipsométricas, y sus títulos se publicarán en castellano, portugués e inglés.

Consideremos por un momento el efecto que puede tener esta empresa mancomunada, de importancia más que continental, sobre los países interesados, en forma individual. Estamos al corriente de los progresos realizados en el campo de la ciencia y el arte en los países civilizados del mundo. Nuestro patrimonio material está distribuido en forma desigual y hasta cierto punto, es de diferentes clases. Resulta de esto que una nación avanza en un solo sentido, aventajando a sus semejantes para ser sobrepasada en otros campos, a su vez. En consecuencia, aprendemos los unos de los otros, emulados a nuestros vecinos, para formar al fin una civilización mejor para todos. Ahora, es muy difícil para el hombre de ciencia suplir determinadas faltas pequeñas y la influencia de los hombres de ciencia en la política de los gobiernos es desigual. Es en este sentido que una empresa cooperativa de estudios seccionales o parciales tiene, 
acaso, mayor interés nacional al participar en esta empresa internacional común, tenemos la seguridad que los diversos gobiernos prestarían mayor atención a las recomendaciones de sus oficinas y asociaciones científicas colaboradoras.

Las estadísticas precisas de producción agrícola y minera recursos hidráulicos, clasificación de los habitantes por familia, razas y vías de migración, son los datos básicos de muchos de los estudios de distribución que he mencionado y serán necesarios para la confección del Atlas que la Sociedad Geográfica Americana espera emprender. Los datos son proporcionados por el Censo, pero el medio para este sistema de medición de los recursos de un Estado es todavía deficiente El historiador Mommsen ha descrito: "El arte de medir pone el mundo bajo el control del hombre..." Una cultura avanzada significa siempre una civilización de "cálculos". El desarrollo y organización comprensiva de cualquier: grupo de la humanidad hacia una "civilización" hubiera resultado imposible sin la facultad de medir y anotar. La geografía se convirtió en ciencia cuando añadió el cálculo a la descripción. Esta es la razón por la que se llama a veces a Eratóstenes el fundador de la ciencia de la geografía: él calculó la circunferencia de la tierra y no concretó meramente a hablar de su redondéz. Sin mapas los administradores políticos y las oficinas científicas - aquellas asesoras indispensables a todo gobierno - dejarían de funcionar en una civilización de alto grado técnico. Un gobierno esclarecido no puede estar conforme al depender únicamente de conjeturas y presupuestos no controlados por cálculos.

Es el deber de todo hombre de ciencia, que sea a la vez un buen ciudadano, informar a su gobierno sobre las necesidades de su país en el campo de la investigación científica y, además, de proporcionarle datos exactos de índole cultural y económica. Estas informaciones son elementos de gran importancia para mejorar la educación, elevar el standard de vida, repartir el peso de los impuestos y proporcionar a todos los ciudadanos un conocimiento de su país que despierte el espíritu de la colectividad y ayude a inculcar el sentido del deber hacia la sociedad en general.

Dado el mayor conocimiento de los hechos y aplicaciones del cálculo que se pueden apreciar en los resultados de los censos, mapas topográficos y de toda la índole, no tardaremos en demandar aquello informes y estadísticas esenciales requeridos por toda buena administración política y por la ciencia geográfica actual. Recordamos con gratitud el ameno libro de James Bryce, "Sud América: observaciones e Impresiones", que dice: "El nexo del Hombre con la Naturaleza es realmente mas estrecho que nunca y mucho más complejo, a pesar del cambio que ha experimentado éste en su actitud hacia Ella". Hacemos bien considerar, por algunos instantes, aquella complejidad y lo que significa para la Sociedad moderna y el Estado. No es una cosa que sea siempre bienvenida o buscada. Se presenta por las mil vías que el comercio brinda, por tierra o mar, por avión, por radio, el film, por tratados, accidentalmente y exprofeso. Nos está cambiando a todos continuamente. De día o de noche, no pasa un solo momento en que estas poderosas fuerzas de reformar el mundo. En vista de tales hechos, ninguna nación puede dejar de considerar las ventajas de un mejor conocimiento de sus propios dominios, sus recursos y sus habitantes. Esto no se dice de acuerdo con ninguna filosofía particularizada social o nacional sino, cualquiera que fuera la forma de gobierno, en favor del bien público y con el espíritu mas ámplio. Es cada día más importante que, en un mundo como el nuestro en el que crecen constantemente la complejidad y la diversidad, trabajemos hacia un mejor entendimiento común, no con expansiones emocionales sin mira determinada, sino mediante estudios prácticos realizados en cordial cooperación y para beneficios mútuos.

No hay pueblo en el mundo tan afortunado que disponga de todas las ventajas que desee. El hombre emplea su ingenio incesantemente para adaptarse a sus recursos según el tipo y zonas de distribución de estos. Cada descubrimiento en el campo de la ciencia exige una nueva apreciación de algunos recursos naturales o grupo de materias primas, otra actitud frente a la investigación y el progreso. En toda esta revalorización 
constante de los recursos de la tierra, los mapas y las estadísticas censuales son los aliados indispensables tanto y las estadísticas censuales son los aliados indispensables tanto del administrador político como del hombre de ciencia. Representan el control de un cálculo preciso que permite al pensamiento alcanzar un criterio más sano, nuevas disposiciones y reglas mejores, progresos en los descubrimientos, el goce de las ventajas de la civilización y un sistema científico de gobierno y de sociedad, en vez de una administración fortuita.

Se está construyendo actualmente un lente de doscientas (200) pulgadas para estudios astronómicos en el Monte Palomar, elemento que contribuirá, de manera asombrosa, a nuestra penetración de los secretos del universo. Este aumento visión en la profundidad del espacio es análogo al perfeccionamiento del equipo para el mejor conocimiento de la tierra que nos brinda la ciencia geográfica mediante hechos y deducciones. Cada refinamiento alcanzado en la técnica de calcular y cada examen de las asociaciones geográficas regionales, nos da un convencimiento más profundo, o por lo menos más vívido, que las complejidades de la vida deben ser fundamentalmente comprendidas si queremos tomar decisiones razonadas en relación con ellas. La geografía de un país es uno de los elementos de su estructura nacional. Esta estructura, a su vez, se refleja en la actitud de un país hacia sus vecinos frente a ciertos problemas generales de comercio y poderío militar que, en relación directa, afecta a toda la familia de las Naciones Unidas.

A modo de comentarios, recomendaciones y/o conclusiones deseamos presentar un resumen del Departamento de Estado de EE. UU sobre la Segunda Conferencia del Instituto Panamericano de Geografia e Historia - IPGH de la OEA en 1935.

\section{El Mapa Millonésimo de la América Hispana ${ }^{3}$}

En 1920 la American Geographical Society de Nueva York inauguró un plan de estudios sobre geografía de México, América Central, América del Sur, y las Antillas. El primer requisito era un mapa general de el área entera a una escala suficientemente grande y con detalle suficiente para servir como base del plan de estudios, para trabajos de reconocimiento en el campo, y para la delineación de los datos obtenidos. La necesidad de compilar un mapa nuevo se debía al hecho de que desde los principios del siglo presente tanto cartógrafos particulares como estabelecimientos cartográficos mercantiles no habian podido mantener el mismo paso con que se acumularon los datos y material cartográfico como resultado del rápido desarrollo de recursos naturales, el desenvolvimiento de la colonización, y la construcción de sistemas de transporte. Era necesario un mapa topográfico-político, al día, que mostrara la topografía del terreno por medio de curvas de nivel y colores hipsométricos y que diferenciara entre curvas de nivel, ríos, y litorales levantados y no levantados. El mapa Internacional del Mundo a la escala 1:1,000,000 parecióse admirablemente a propósito para los fines deseados y fue escogido para el mapa propuesto. Este mapa llegó a ser una gran empresa cooperativa, mereciendo la ayuda de departamento gubernamentales de los países hispano-americanos, instituciones científicas, compañías de construcción y de explotación, e individuos particulares en los países hispanoamericanos y otros países, en la colección de material para la compilación. Del total de 102 hojas necesarias para cubrir las extensiones terrestres de México, la América Central, la América del Sur y las Antillas, se han publicado 52 hojas, y las 50 hojas restantes se han compilado y serán dibujadas hasta fines de 1935. La publicación del mapa completo se terminará hacia julio de 1936. Las hojas que se han dado a la luz y muchas de las complicaciones ya se han utilizado extensivamente. Poco después de que se haya terminado la publicación del mapa entero se publicará un libro detallando el procedimiento empleado en la compilación. Este mapa satisfacer una gran necesidad, ya como obra de referencia, ya como mapa general sirviendo como base para la prosecución de muchísimos ramos de estudio y averiguación. Además de incluir todos los datos disponibles sobre topografía, tamaños de pueblos y ciudades, límites internacionales, subdivisiones administrativas, y las líneas de comunicación y redes de transporte, este mapa se 3 Resumen de la exposición del Dr. Raye R. Platt; Secretario de la Sociedad Geográfica Americana de Nueva York durante la 2da Asamblea General del IPGH en 1935 en EE.UU. 
ha levantado de tal manera que a primera vista muestra las mediciones levantadas, la naturaleza de dichas mediciones, y la localidad y características de las regiones que todavía aguardan los pasos de explorador.

\section{Referencia Bibliográfica}

Bowman, I. (1911) Forest physiography; physiography of the United States and principles of soils in relation to forestry. [New York, J. Wiley \& sons; etc., et] [Web.] Retrieved from the Library of Congress, https://lccn.loc.gov/11029383.

Bowman, I. (1916) [1938]. The Andes of Southern Peru; Geographical Reconnaissance along the Seventy-Third Meridian, Published for The American Geographical Society of New York by Henry Holt and Company. Traducido por Carlos Nicholson. Editorial La Colmena S.A. Arequipa, Perú. 268 p.

Bowman, I. (1921). The New World; problems in political geography, World Book Company, Nueva York.

Bowman, I. (1924). Desert Trails of Atacama (American Geographical Society, New York, Special Publications No 5, 362 p.).

Bowman, I. (1924). The New World: Problems in Political Geography (ed. revisada y ampliada). London: George G. Harrap \& Co.

Bowman, I. (1927). Some German Works on Political Geography. Geographical Review, 17(3), $511-513$.

Bowman, I. (1934). Geography in Relation to the Social Sciences (Report of the Commission on the Social Studies, American Historical Association., Part 5). New York: Charles Scribner's Sons.

Bowman, I. (1937). A New Chapter in Pan-American Cartography. En Melanges de geographie et d'orientalisme offerts a E.-F. Gautier (pp.88-95). Tours: Arrault et Cie. 